international workshop about multiple topics (e.g. different organs, STIs, sexual health, conception or pregnancy). Local implementation is driven by various projects of the participants.

Since 2009 an Austrian Group is working within "HIV and Your Body" using simultaneously different communication strategies.

The presented work aims to evaluate the impact of the chosen multidimensional communication strategies on health awareness and behavioural changes in PLHIV in Vienna/Austria, providing recommendations for optimising such informational programmes in regard of true-to-life needs of PLHIV.

Results Until now the Austrian group provided intensive seminars, peer-to-peer support and individual counselling within „HIV and Your Body". Simultaneously information was spread by information events and publications (e.g. brochures, magazine, newsletter and broadcast). The amount of reached persons was directly associated with individual or public setting, with a broad range up to 34.000 (detailed numbers will be presented).

Contact numbers achieved in Austria underline importance of the topics and present needs of PLHIV for information and support concerning individual health.

Previous feedback has been promising that the chosen combination of information channels enhances the aim of informational programmes.

An ongoing survey aims to evaluate the effect of combined communication approaches as well as further communication requirements. Evaluation data will be presented.

Conclusion Based on evaluation results future projects within "HIV and Your Body" in Austria can be optimised.

General recommendations for communication strategies promoting individual health awareness and supporting healthy lifestyles of PLHIV will be discussed.

\section{P4.099 DEVELOPMENT OF TRAINING MODULES TO ADDRESS HEALTH WORKER STIGMA AND DISCRIMINATION AGAINST MSMS AND TRANSGENDERS IN MALAYSIA, INDONESIA, PHILIPPINES AND TIMOR LESTE- THE ISEAN-HIVOS PROGRAM APPROACH}

doi:10.1136/sextrans-2013-051184.0997

\section{P Norella. ISEAN Hivos Program, Jakarta, Indonesia}

Background The ISEAN-Hivos Program is a Regional Global Fund Program that focuses on reducing the vulnerability and risks of MSM and TG to HIV infection in Insular Southeast Asia. The Program also intends to address critical gaps in supporting and scaling up activities that reduce HIV/AIDS among MSMs and TGs. One of the key strategies of the Program is the development and implementation of training modules that address stigma and discrimination among health workers when they provide clinical and related services to MSMs and TGs, particularly in Indonesia, Malaysia, the Philippines and Timor Leste. This study describes the strategy used by the ISEAN-Hivos Program towards achieving this goal.

Methods Based on strategy evaluations, it was deemed that the modules need to include clinical skills training for the health workers, as a springboard towards changing their negative attitudes about their MSM and TG clients.

Results Key initial findings while preparing the modules include the following:

1. There is a need to engage country-recognised "experts" that can provide the trainings.

2. There is a need to engage the Ministries of health in the four countries to enable the module to be used as well by health care workers in public settings.

3. The modules must be flexible enough to be able to be tailored in terms of content, length of training and level of skills or knowledge required, depending on the needs of the targeted health care workers' contexts.
Conclusion The findings from the initial strategic evaluation of the approach used in the development of training modules that address healthcare workers' stigma and discrimination against MSM and TGs who seek STI-HIV-related services support a multiagency approach working at a regional level. The modules will then be translated into local languages for ease of use among the target training participants.

\section{P4.100 MEASURING ADHERENCE TO ANTIRETROVIRAL THERAPY IN NORTHERN TANZANIA: FEASIBILITY AND ACCEPTABILITY OF THE MEDICATION EVENT MONITORING SYSTEM}

doi:10.1136/sextrans-2013-051184.0998

\section{E F Msoka. Kilimanjaro Clinical Research Institute, Moshi, Tanzania}

Background An often-used tool to measure adherence to antiretroviral therapy (ART) is the Medication Event Monitoring System (MEMS), an electronic pill-cap that registers date and time of pillbottle openings. Despite its strengths, MEMS-data can be compromised by inaccurate use and acceptability problems due to its design. These barriers remain, however, to be investigated in resource-limited settings. We evaluated the feasibility and acceptability of using MEMS-caps to monitor adherence among HIVinfected patients attending a rural clinic in Tanzania's Kilimanjaro Region

Methods Eligible patients were approached and asked to use the MEMS-caps for three consecutive months. Thereafter, qualitative, in-depth interviews about the use of MEMS were conducted with the patients. MEMS-data were used to corroborate the interview results.

Results Twenty-three of the 24 patients approached agreed to participate. Apart from MEMS-use on travel occasions, patients reported no barriers regarding MEMS-use. Unexpectedly, the MEMS-bottle design reduced the patients' fear for HIV-status disclosure. Patients indicated that having their behaviour monitored motivated them to adhere better. MEMS-data showed that most patients had high levels of adherence and there were no bottleopenings that could not be accounted for by medication intake. Non-adherence in the days prior to clinic visits was common and due to the clinic dispensing too few pills.

Conclusion MEMS-bottle use was readily accepted by patients. Although the MEMS-bottle was used accurately by most patients, patients need to be more explicitly instructed to continue MEMSuse when travelling. Even HIV-clinics with sufficient staff and free medication may impose structural adherence barriers by supplying an insufficient amount of pills.

\section{P4.101 WITHDRAWN BY AUTHOR}

\section{P4.102 PILOTING CONTINGENCY MANAGEMENT INTERVENTION AMONG NEEDLE EXCHANGE PROGRAM USERS IN TIRANA, ALBANIA}

doi:10.1136/sextrans-2013-051184.0999

${ }^{1}$ A Boci, ${ }^{2} \mathrm{~A}$ Zazo, ${ }^{1}$ E Hallkaj. ${ }^{1}$ STOP AIDS NGO, Tirane, Albania; ${ }^{2}$ UNICEF, Tirane, Albania

Background Although Needle Exchange Programs (NEP) are a great tool in fighting HIV/AIDS and yielding a significant cost savings for intravenous drug users (IDU) the challenge of the programme remains the irregular uptake of services from the clients and attracting new clients. Contingency Management (CM) is widely known as an intervention that addresses behaviours concerns. It provides tangible rewards for clients to increase or decrease the frequency of concrete target behaviours. The programme hypothesised that using the reward system via CM might help 
better engage with the clients, ensure regular use of services and gain new clients.

Methods 80 NEP users were recruited and equally divided into two groups, the experimental and control one. Implementation phase was followed by: Development of CM protocol, identification of the desired behaviours that an IDU client should change and maintain, establishment of the reward mechanism and monitoring and evaluating outcomes.

Results In comparison with control group clients, participants of the CM group had higher rates (up to three fold) of daily attendance of NEP services. All of them have been tested for HIV and HVC in comparison with $35 \%$ of control groups, and one third of them brought their sexual partners to be tested. $15 \%$ have invited programme team (home visits) to discuss with their sexual partner/ family members. In addition, was significantly increased the number of female IDUs who have been introduced to NEP by CM participants.

Conclusions CM approach indicates the need for using innovative interventions to attract and motivate IDUs clients in using on regular basis HR programmes, especially for hard to reach subgroups of IDUs, such as female drug users or IDUs sexual partners. Regular uptake of HR services implies reductions in injection-related drugtaking behaviours and therefore lesser risks for getting or transmitting HIV/HVB\&C.

\section{P4.103 ASSESSING INTENTIONS OF DENTISTS FOR PROVISION OF DENTAL TREATMENT TO THE PATIENTS LIVING WITH HIV/ AIDS (PLWHAS) IN PAKISTAN}

doi:10.1136/sextrans-2013-051184.1000

A A Khawaja Khail, A S Gichki, K A Alizai, S A Kurd, M A Raisani. Bolan Medical College, Quetta, Pakistan

A cross-sectional survey was carried out in Balochistan province in Pakistan to assess the intentions of dentists to provide dental treatment to the patients living with HIV/AIDS. All dentists of Balochistan province, registered by Pakistan Medical \& Dental council (PMDC) were the population of this study and all the dentists either working in government sector, private sector or both were included.

Data collection was done by using mailed questionnaire among 115 dentists and 86 questionnaires were received with a response rate of $74.8 \%$.

On statistical analysis, it was revealed that only $25 \%$ of the dentists expressed their willingness to provide dental treatment to the

\begin{tabular}{lll}
$\begin{array}{l}\text { Abstract P4.103 Table } \mathbf{1} \\
\text { treatment to PLWHAs }\end{array}$ & Number & Percent \\
\hline Intentions to provide treatment & $\mathbf{5 1}$ & $\mathbf{5 9 . 3}$ \\
\hline Refer to specialised clinic & $\mathbf{2 0}$ & $\mathbf{2 3 . 3}$ \\
Provide treatment & 9 & 10.5 \\
- Treat him/her as a normal patient & 4 & 4.7 \\
- Only conduct procedures which do not involve blood & 3 & 3.5 \\
- Charge more for the disposables & 2 & 2.3 \\
- If the patients general health is good & 1 & 1.2 \\
- Treat in government hospital but not in clinic & 1 & 1.2 \\
- Only treat if mode of transmission is not sexual & $\mathbf{1 5}$ & $\mathbf{1 7 . 4}$ \\
Refuse to provide treatment & 6 & 7.0 \\
- Lack of proper equipments & 4 & 4.7 \\
- Fear; because HIV has no cure & 3 & 3.5 \\
• Very inconvenient (Safety precaution) & 2 & 2.3 \\
• No experience; not sure how to treat & & \\
\hline
\end{tabular}

patients living with HIV/AIDS. On the other hand $17 \%$ of the dentists would refuse to provide dental treatment to PLWHAs.

Of those who intent to provide treatment; $10 \%$ of the 86 dentists will treat such patients as a normal patient. Those dentists who would prefer to refuse the PLWHAs; $7 \%$ of 86 dentists will refuse due to lack of proper instruments and sterilisation equipments and around $5 \%$ will refuse because of fear, as HIV has no cure.

Our results revealed that the dentists had a false sense of contraction of HIV because of lack of knowledge and social myths. According to the previous studies risk of contraction of HIV in dentistry is very low $(0.3 \%)$. Our results also revealed that the main reason for denial to provide treatment to PLWHAs was lack of proper instruments and equipment.

\section{P4.104 IMPACT OF BEHAVIORAL CHANGE COMMUNICATION AMONG MSM OF HYDERABAD, PAKISTAN}

doi:10.1136/sextrans-2013-051184.1001

M Osama. Naz Male Health Alliance, Lahore, Pakistan

BCC result After the BCC in the city Hyderabad, Pakistan of almost 4000 MSM results shows, the average age of MSM was 26 years old, around $40 \%$ of them are uneducated and $60 \%$ had primary or secondary education, and $63 \%$ was unmarried. Anal intercourse, masturbating each other and blow job were the main sexual behaviours. The awareness rate of AIDS/STD-related knowledge was not more than $15 \%$. The infection rate of HIV is $2 \%$ and STI is $43 \%$ respectively.

Suggestion The results suggest that HIV transmission control, effective education and behaviour intervention should be strengthened. A detailed BCC strategy should be plan based on the information from mapping of behaviours, practises and attitudes of MSMs, and their clients and partners.

Conclusion The BCC needs of the MSM community with regard to STD/HIV/AIDS intervention programme and suggest the communication needs of the population, especially the high vulnerability groups, which would aid in designing communication programmes that focus on the BCC component of the HIV/AIDS prevention strategy including planning, formative research, message development, material design, pre-testing, dissemination, implementation and monitoring.

\section{P4.105 INTERGRATING HIV COUNSELLING AND TESTING ACTIVITIES WITH STI SERVICES INCREASES ACESS AND UTILISATION TO HIV/AIDS CARE AND SUPPORT SERVICES}

doi:10.1136/sextrans-2013-051184.1002

P Ndawula, J Ggita, S C Nanziri, S Kabwigu, S A Nanyonga, H S Luwuge, T Nakyanzi, D Kemigisha. Makerere university-Johnhopkins university research collaboration, Kampala, Uganda

Background STIs and HIV are both mainly sexually transmitted. They share the same behaviour and sexual risk factors. Studies have shown that STDs enhance the sexual transmission of HIV and on the other hand.HIV/AIDS alters the clinical course of most STIs and related complications have consistently ranked among the leading causes of outpatient consultations in public health facilities accounting for about $20 \%$ of adult out patients' consultations. Health workers have continued to manage STD patients at all levels without referring them for an HIV test. Those referrals that do take place are often undocumented, because many health workers do not feel confident enough to discuss HIV/AIDS with their clients and may not see the importance of linking the two together. Description: MU-JHU supported HIV interventions in19 central districts of Uganda. It contributed as a partner to $\mathrm{MOH}$ review of existing STD training guidelines and treatment algonthms. The revised materials 